Article

\title{
A Comprehensive Model to Study the Dynamic Accessibility of the Park \& Ride System
}

\author{
Jairo Ortega ${ }^{1, * \mathbb{C}}$, János Tóth ${ }^{1}$ and Tamás Péter ${ }^{2}$ (D) \\ 1 Department of Transport Technology and Economics, Faculty of Transportation Engineering \\ and Vehicle Engineering, Budapest University of Technology and Economics, 1111 Budapest, Hungary; \\ toth.janos@kjk.bme.hu \\ 2 Department of Control for Transportation and Vehicle Systems, Faculty of Transportation Engineering \\ and Vehicle Engineering, Budapest University of Technology and Economics, 1111 Budapest, Hungary; \\ peter.tamas@mail.bme.hu \\ * Correspondence: jairo.ortega@kjk.bme.hu
}

Citation: Ortega, J.; Tóth, J.; Péter, T. A Comprehensive Model to Study the Dynamic Accessibility of the Park \& Ride System. Sustainability 2021, 13, 4064. https://doi.org/10.3390/ su13074064

Academic Editor: Francesca Pagliara

Received: 24 February 2021

Accepted: 1 April 2021

Published: 6 April 202

Publisher's Note: MDPI stays neutral with regard to jurisdictional claims in published maps and institutional affiliations.

Copyright: (c) 2021 by the authors. Licensee MDPI, Basel, Switzerland. This article is an open access article distributed under the terms and conditions of the Creative Commons Attribution (CC BY) license (https:// creativecommons.org/licenses/by/ $4.0 /$ )
Abstract: A Park and Ride (P\&R) system is an intermodal point where private vehicle users transfer to public transport to make a combined trip. Several researchers have measured the static accessibility of the P\&R system. However, studying dynamic accessibility leads to a comprehensive model consisting of a series of elements and steps that allow for travel time analysis in various traffic conditions. Therefore, the purpose of this article is to develop an integrated model that provides a set of procedures which determine the travel origin points of the $P \& R$ system, calculate the trips in different traffic conditions (in this article, the results are shown in three scenarios: no traffic (NT), low traffic (LT), and heavy traffic (HT)), and include a hot spot analysis and correlation in order to finally be able to display the dynamic accessibility using geospatial software. The result shows that the accessibility of the P\&R system varies depending on the traffic volume and the variation of the accessibility in the different areas that conform to the urban environment. In conclusion, the integrated model helps users decide on the best time to travel to the P\&R system, allows transport planners to develop strategies to make the system more functional, and gives an excellent opportunity to develop a travel information system.

Keywords: sustainable urban mobility plan; park and ride; mobility type; dynamic accessibility; public transport

\section{Introduction}

Accessibility in the field of transport is generally characterized as possible contact with spatially-distributed opportunities to reach a location, and is usually defined as physical access to goods, services, and destinations [1]. It is one of the essential components in the study of the transport system in the sense of urban economy and geography [2], and it is an indicator of the effectiveness of the region or location relative to other zones and regions [3]. For improved access to public transport, better accessibility to public services is a requirement [4]. In fact, accessibility has become a key concept in geography, transport, and urban planning. It has also become crucial for users to make the most suitable alternative according to parameters such as traffic, energy consumption, and travel time $[5,6]$.

When getting a clear concept of accessibility in a transport system, accessibility can be involved or measured in the park and ride (P\&R) system. The P\&R system is a connection point between private and public transport, and it is mostly used by people who live in the outskirts of the city, where public transport coverage is inefficient or non-existent. However, in the urban area, and specifically in the city center, congestion problems cause these users to switch to public transport, which is directly connected to the CBD (Central Business District) through the P\&R system $[7,8]$. Analyzing this concept, the accessibility 
study of the P\&R system is associated with the accessibility of private and public transport from the origin of the trips to their destination [9].

Accessibility can be measured in private transport from an origin to a destination in different traffic conditions, and for the public transport, it is associated with the frequency of service and the travel time from the P\&R to the destination. This means that accessibility is dynamic and varies according to the time and the day. Dynamic accessibility can determine the departure time in order to provide the $P \& R$ user adequate access to public transport [10]. However, most of the pre-existing accessibility metrics are static, which characterize the conditions of peak hours or only the daily average.

Thus, a dynamic accessibility study for a P\&R system aims to develop a method to determine those origin points of the trips which a $P \& R$ system can attract. The traffic conditions under which vehicle users move from the origin to the $P \& R$ system determine which type of P\&R facility they choose according to the travel time [11]. Another determinant of the travel conditions is made by public transport from the P\&R facility to the destination. This includes the timetables and the level of service [12].

The development of extensive data analysis in recent years has led to the emergence of dynamic accessibility that captures temporal variations on accessibility as an important focus of research, and some researchers have achieved certain results in this area [13]. After all, residents do not require every urban area to have the same accessibility at all times, assuming that they can comfortably access relevant points of interest, especially those located in nearby areas along their usual travel routes [14]. Few studies on dynamic accessibility have addressed measurement applied to the $P \& R$ system and relevant geographical areas [15].

The main question of this study is how to compare the dynamic accessibility under different traffic conditions of the origin points of the trips to the P\&R system from each zone of the urban environment of a city. Here, accessibility is measured as the sum of the number of origin points within a zone from where the $P \& R$ system is used under the given traffic conditions in a given period of time in a day. The parameter on which the comparison is based is travel time. Our study uses data from a Latin American city called Cuenca in Ecuador, where we studied seven possible P\&R facilities [16]. The methodology for measuring accessibility proposed in this paper may benefit cities in developing countries with limited resources.

The article is structured as follows. Section 2 describes the work carried out by researchers on accessibility in various transport systems, and overviews the literature on P\&R systems. Section 3 describes the methodology and data collection applied here to develop the model to determine the dynamic accessibility. Section 4 shows the results produced using maps and tables and includes a discussion of the findings. Finally, the conclusions section describes the principal discoveries, advantages, and limitations of the methodology developed here and identifies future research directions.

\section{Literature Review}

The link of the public and private transport system highly contributes to our daily life. While there are many studies on the accessibility of public and private transport systems, the accessibility of the P\&R system is less researched. However, it is interesting how studies on accessibility in public and private transport through the P\&R system can be illustrated. In the following, relying on numerous publications, we describe the literature on accessibility in public and private transport and the operation of the P\&R system.

Accessibility research began years ago and focused primarily on the capacity and alternatives available to reach a destination [17-19]. The core principle of a city's urban planning is connectivity with the various transport systems [20-22]. In recent decades, accessibility analysis has played an important role in studying land use and transport [23]. The recent increase in techniques that allow for high-resolution data collection has led to the rise of studying dynamic accessibility that accurately captures temporal differences in accessibility over periods of time [24]. Dynamic accessibility, measured for travel times, 
relies on the various modes of transport and plays a significant role in varying times with shifts in the transport network and destinations of people's activities [25]. The outcomes of a dynamic accessibility measurement for public transport and private mode will be substantially different in different circumstances. Thus, it is more reliable to measure accessibility for each transport mode as a separate unit [26]. Deep analyses have also been done on what aspects of accessibility people have via a given means of transport, such as the train, the bus, the automobile, and the taxi [27-30]. A technique that incorporates data from current geographic information systems for the purpose of offering a real-time measurement of the accessibility and connectivity of transport modes is described in [31,32]. In addition to studying the dynamic accessibility of a mode of transport, we can measure the accessibility of the different transport modes and then compare them [33]. Accessibility to public transport in Hong Kong has proven to be much higher than that of a private car because of comparatively low monetary costs and the high standard of public transport services [34].

Private cars have created adverse effects in urban environments such as traffic and pollution. Researchers dealing with this subject have made a range of recommendations to local governments to address these issues. One of these approaches suggests a complete change from private cars to an environmentally friendly mode of travel (e.g., walking, cycling, public transport) [35-39]. However, this is not an option for people who own a private car and live outside the metropolitan area with limited or no available public transport service [40]. Thus, researchers and transport planners have studied and found methods and methodologies to examine the components of a P\&R system and figure out the most relevant components for researchers to study [41,42]. For example, the capacity of the P\&R system has been investigated, which relates to the number of parking spaces needed in the P\&R system [43]. Furthermore, demand and travel times are examined by analyzing the relationship between the P\&R system and the public transport system elements [44]. Travel time in the first part of the trip by a private car to the P\&R system can depend on the location of the facility and the time of day analyzed. For example, traffic could be higher in the morning during peak hours and lower during the night in lower activity hours. A multimodal equilibrium model including three modes of transport was developed to analyze the locations and subsequent optimization of existing P\&R facilities in order to understand the P\&R system as it interacts with public transport $[45,46]$. Besides, the location of the P\&R system is closely related to the features of the transport system, such as the possible number of users and the proximity of the facilities to public transport stations [47-50]. To better understand the components of the P\&R system and the accessibility, it can be represented and studied through geographic information systems (GIS) [51].

Our review of accessibility found that few previous dynamic accessibility studies focused on the accessibility of the P\&R system. Earlier studies often used a generic accessibility index to measure accessibility and effectiveness by dividing cities into small grids or transport study areas without relying on the individuals' real origin points and related travel zones [52]. This paper suggests an analytical approach to study the dynamic accessibility of P\&R facilities through real journeys. For this purpose; the methodology includes the origins of the trips known as starting points of the P\&R system. Then an algorithm is applied to study the travel time in a private vehicle in different traffic conditions (non-traffic, heavy and low traffic) from given starting points, and finally a GIS tool is used to interpret the dynamic accessibility through a visual approach.

\section{Data and Methodology}

In this part of the study, the methodology to determine the dynamic accessibility of the P\&R system is presented. The data coming from the existing mobility plan of Cuenca, Ecuador is described, and the case study is presented. Finally, it is shown how the methodology of dynamic accessibility of the P\&R system was developed step by step. 
The final result is a comprehensive approach to measure the dynamic accessibility of the P\&R system.

\subsection{Study Area}

The P\&R system is relatively new in the city of Cuenca, Ecuador. It has rather been studied theoretically to enable intermodal transport between private vehicle users who live on the periphery of the city or where access or coverage by public transport service is limited. The city is composed of 15 zones. Light rail transit (LRT) constitutes the most modern transport system in the city, which is connected to seven P\&R facilities (marked from $A$ to $G$ ) that have been discussed in the research carried out by Ortega et al. $[16,53]$ (see Figure 1). Regarding the connections of the P\&R system, they are made through secondary road networks. The entrance to the city from the north is through zones 1 and 11. The entrance to the city from the east is in zone 15, and from the west, it is in zone 3. The entrance from the south is in zone 14.

The city has also developed a SUMP (Sustainable Urban Mobility Plan) as part of its efforts to promote sustainable mobility among its citizens. The plan chapters contain data that can be used in subsequent studies, such as division into zones and land use. Besides, chapters containing parking policies serve as a basis for future studies. The historical center is classified as a World Heritage Site by the UNESCO. One of the recurrent problems is the high level of congestion in the center of the city. Orellana et al. [54] carried out several studies in the area of mobility. The authors offered analyses on the effect of the spatial design of street networks and the mobility of bicycle users. Besides, Hermida et al. [55] explored the influence of the built environment on traffic flow.

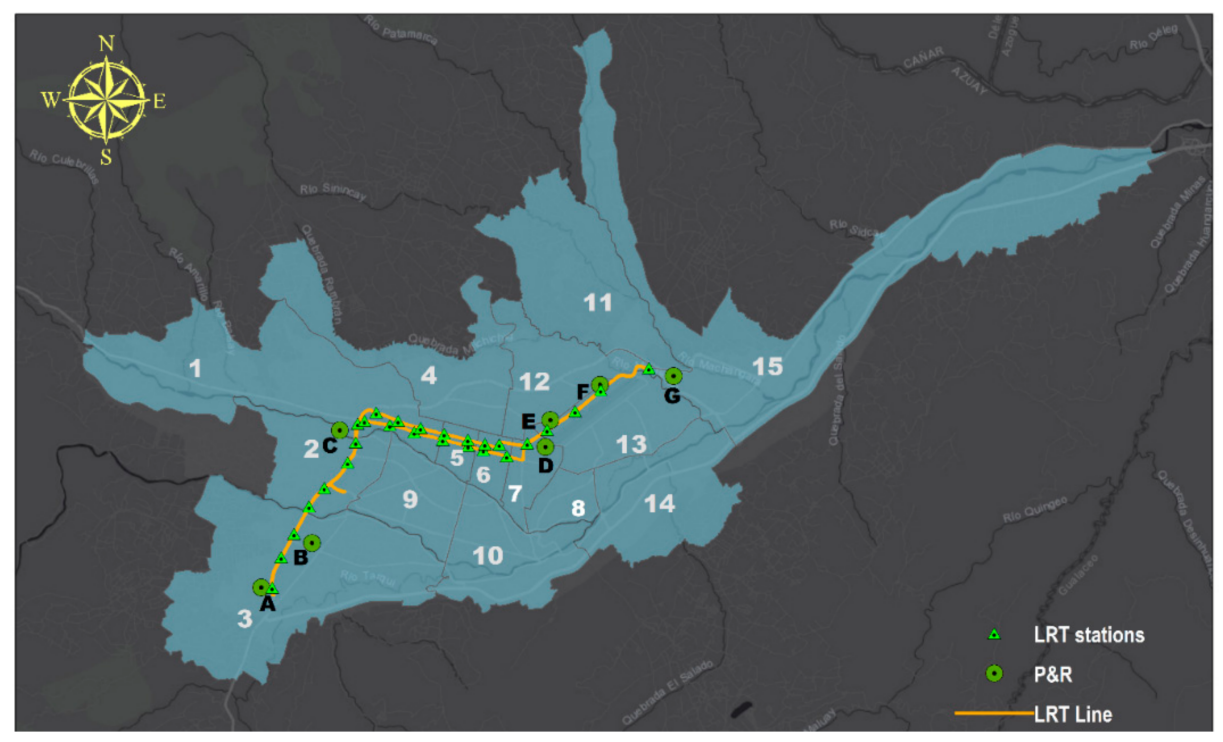

Figure 1. The Park and Ride (P\&R) system, light rail transit (LRT), and zonal division of Cuenca, Ecuador.

Cuenca is officially the capital of the province of Azuay. The city has 329,928 inhabitants, making it the third most populated settlement in the country behind Quito and Guayaquil. The city is made up of rural and urban districts. The conglomerate is comprised of 661,685 inhabitants.

The Terminal Terrestre is the central bus station, located in zone 12. Its function is to receive passengers arriving from other cantons and provinces of the country. Since 2008, the city has been implementing a program called the Intelligent Transportation System of Cuenca, which includes the installation of new intelligent LED traffic lights, the modernization of buses circulating in the city, the construction of two transfer stations, as well as the Cuenca Tram. The city buses are blue and red, and are organized according to a 
group of numbered routes. The main urban lines are Troncal 100 and Troncal 200, which will be integrated with the tram system and transfer station feeders. The city has 3557 cabs in force that provide conventional cab service. The use of the taximeter is mandatory.

The SUMP developed by the municipality provides for origin-destination trips on different modes of transport in the city, with the CBD (zones 5, 6, 7) being the leading destination with about 600,000 daily trips. Among these, $32 \%$ are made by private vehicles. In terms of trips from outside the urban area to the city, there are 24,140 trips generated by private vehicles. From these trips, $11.89 \%$ are work-related activities and $6.2 \%$ for commercial purposes [56].

\subsection{Selecting Origin Points}

The selection of the origin points begins with the information available in the mobility plan of the city, in which there is a division based on zones and areas of land use and activity. This selection was made as a first step through the georeferenced information of each point of origin within each zone with respect to the following land use categories [57]:

1. Residential use;

2. Commercial use;

3. Recreational use;

4. Agricultural use.

The method aims to choose the ideal subzones that generate travel through the P\&R facilities. For example, it is assumed that sub-areas characterized by recreational and agricultural land use do not generate travels to the $P \& R$ mode as the population engaged in these activities prioritize the use of other modes of transport. However, most journeys, both commercial and residential, are potential beneficiaries of the P\&R mode. The selection of the origin points to create an origin and destination matrix in the P\&R system was already determined in a study carried out by Ortega [16], which identified 655 origins based on the land use and activity of the potential users of the P\&R system. Of a total of 982 georeferenced points, after classification, 655 origin points are considered.

\subsection{Road Traffic Data Collection}

Travel time is calculated between the previously determined origin and destination points and the location of the P\&R facility. Thus, the travel time is calculated in three traffic conditions:

1. Travel time, without traffic (NT);

2. Travel time during low traffic on the network (LT);

3. Travel time during heavy traffic on the network (HT).

Heavy traffic is defined according to the mobility plan, as the hours when the travel time of a private vehicle driver travelling from an origin to a destination increases due to the large number of vehicles wishing to make the same trip.

Low traffic refers to a time when a private vehicle driver from an origin to a destination travels within the average travel time. Each city has a different number of heavy traffic or low traffic hours.

These metrics were chosen because they have generally been considered as indicators of accessibility. The average distances and the travel times are calculated for each origin point of the zones with the applied algorithm.

The Google Maps Address API [58] service calculates the exact travel time between sets of origins and destinations on a transport network based on an actual traffic condition.

\subsection{Public Transport Travel Time}

The municipality of Cuenca provided the public transport (LRT) data in terms of frequency, travel time, and distance between stops. The LRT operates from Monday to Sunday from 6:00 to 21:00 with a 10 min frequency. Furthermore, the average transfer time from the $P \& R$ facilities to the LRT station is $5 \mathrm{~min}$, which means a maximum transfer 
time of $15 \mathrm{~min}$ to access public transport. Besides, the maximum travel time from a P\&R facility to the city center by LRT is $20 \mathrm{~min}$. This information is provided as part of the city's LRT planning and construction study by the department of transport operations, and the municipality of Cuenca [56].

\subsection{Dynamic Spatial Accessibility of the PER System}

Using the data obtained through data collection and algorithms to calculate travel time, this data can then be entered into a geospatial program to analyze dynamic accessibility. In the geospatial software used, the hot spots of the trip origins of the P\&R system are analyzed, indicating the level of accessibility of these points through a set of colors. For example, a red point indicates that it is a hot spot, a blue point indicates that it is a cold spot, and the intermediate colors indicate the tendency of accessibility. In addition to calculating the correlation, this method allows for ensuring that the origins of the trips be calculated according to their functionality. The final result of the methodology will provide a map for each traffic condition of dynamic accessibility and a degree of travel time fluctuation.

The hot spots analysis would start with a first analysis of the spatial aggregation of the data. To apply the hot spot analysis methodology, a specific typology has been selected in our case: travel time in three traffic scenarios. Thus, we can simulate the detailed and thorough analysis that would be carried out on a specific problem. Hot spot analysis also reveals that there are patterns of concentration of trip origin points of a transport system in different zones and specific to each subzone; in other words, they are not random. Therefore, in order to measure the accessibility of the P\&R system, which is considered a transport mode in a medium-sized city where the points of origin of trips are not random, the hotspot method is the most suitable approach.

\subsubsection{Hot Spots Formulation}

Hot spot analysis identifies where travelers are going with high or low time accumulations and compares travel times for individual origins with travel times from neighboring origins. The following Equations (1)-(3) explain the method used to calculate the hot spots:

The Getis-Ord local statistic is given as:

$$
G_{i}^{*}=\frac{\sum_{j=1}^{n} w_{i, j} x_{j}-\bar{X} \sum_{j=1}^{n} w_{i, j}}{S \sqrt{\frac{\left[n \sum_{j=1}^{n} w_{i, j}^{2}-\left(\sum_{j=1}^{n} w_{i, j}\right)^{2}\right]}{n-1}}}
$$

where $x_{j}$ is the attribute value for feature $j, w_{i, j}$ is the spatial weight between feature $i$ and $j, n$ is equal to the total number of a feature:

$$
\begin{gathered}
\bar{X}=\frac{\sum_{j=1}^{n} x_{j}}{n} \\
S=\sqrt{\frac{\sum_{j=1}^{n} x_{j}^{2}}{n}-(\bar{X})^{2}}
\end{gathered}
$$

The $G_{i}^{*}$ statistic is equal a $z$-score, thus no further calculations are required.

The $G_{i}^{*}$ statistic returned for each entity in the dataset is a $z$-score. For positive $z$-scores that are statistically significant, the larger the $z$-score is, the more intense the clustering of high values (hot spot) should be. For negative $z$-scores that are statistically significant, the smaller the $z$-score is, the more intense the clustering of low values (cold spot) should be.

The result of the study by the statistician Getis-Ord $G_{i}^{*}$, and in it, we can see how the origin points of a P\&R system create a hot spot (z-positive scores), while negative $z$-scores create the so-called cold spots. Those zones have problems of accessibility according to traffic conditions in the city's urban environment that have more cold spots in them.

The Hot Spot Analysis tool is part of the software used. This tool works by searching for each entity within the context of neighboring entities. An entity with a high value is 
interesting, but may not be a statistically significant hot spot. To be a statistically significant hot spot, an entity must have a high value and also be surrounded by other entities with high values. The software package itself gives the formula. The data needed are the origin of trips and the travel time in different traffic metrics.

\subsubsection{Correlation Formulation}

In statistics, Moran's I is a measure of spatial autocorrelation developed by Patrick Alfred Pierce Moran [59]. It is characterized by a correlation in a series of indicators among nearby locations in the spectrum. The correlation equations are presented below (Equations (4)-(8)):

The Moran's I statistics for spatial autocorrelation is given as:

$$
I=\frac{n \sum_{i=1}^{n} \sum_{j=1}^{n} w_{i, j} z_{i} z_{j}}{s_{0} \sum_{i=1}^{n} z_{i}^{2}}
$$

where $z_{i}$ is the deviation of an attribute for feature $I$ from its mean $(x i-\bar{x}), w_{i j}$ is the spatial weight between feature $i$ and $j, n$ is equal to the total number of features, and $s_{0}$ is the aggregate of all spatial weights.

$$
I=\frac{n \sum_{i=1}^{n} \sum_{j=1}^{n} w_{i, j} z_{i} z_{j}}{s_{0} \sum_{i=1}^{n} z_{i}^{2}}
$$

The $Z_{I}-$ score for the statistic is computed as:

$$
Z_{I}=\frac{I-E[I]}{\sqrt{V[I]}}
$$

where:

$$
\begin{gathered}
E[I]=-\frac{1}{n-1} \\
V[I]=E\left[I^{2}\right]-E[I]^{2}
\end{gathered}
$$

With respect to Moran's Global Index, the value $P$ is 0 , and the null hypothesis can be rejected; in other words, there is a state of spatial dependence in the distribution of values. Given a set of origin points of the P\&R system and an associated facility attribute, this tool assesses whether the expressed pattern is clustered, dispersed, or random. When the $z$-score and the $p$-value indicate statistical significance, a positive value of Moran's I-index indicates a trend towards clustering. In contrast, a negative value of Moran's I-index indicates a trend towards dispersion.

The Spatial Autocorrelation tool outputs are five values: Moran's I-index, the expected index, the variance, the $z$-score, and the $p$-value. These values can be accessed in the Results window. The formulation comes within the software used, and the data needed is the location of the origin points and travel time in different traffic metrics.

To understand more about the model that makes the study of the dynamic accessibility of the P\&R system possible, the following diagram (Figure 2) explains the functioning of the model in which the final result is the visualization of the level of accessibility on a map. 


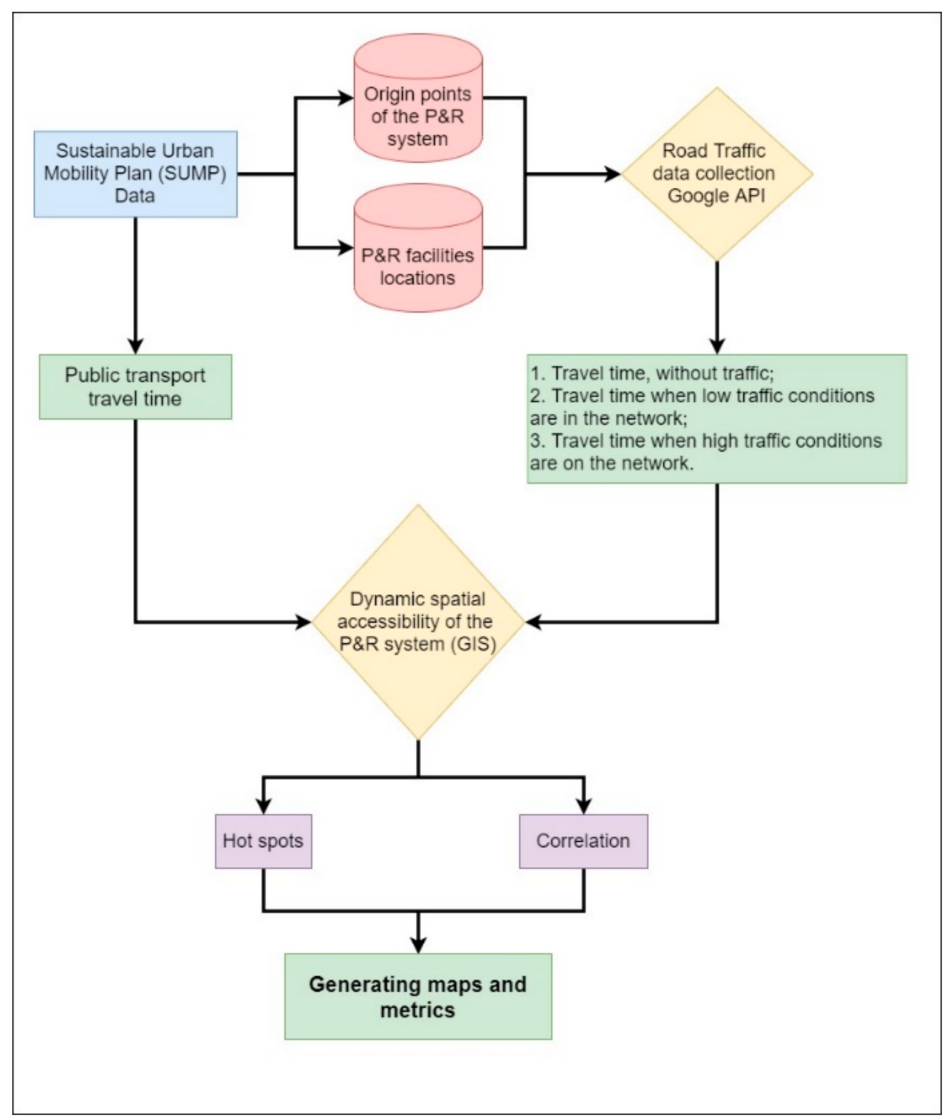

Figure 2. Diagram of the model to study the dynamic accessibility of the P\&R system.

\section{Results and Discussion}

The results obtained serve as the basis for creating maps that allow for visualization. Additionally, for each series of results, an extensive description has been presented, which serves as a basis for understanding the relevance of what has been generated.

\subsection{Hot Spots Analysis}

In the first series of maps, hot spots in the three traffic scenarios are studied (Figures 3-5).

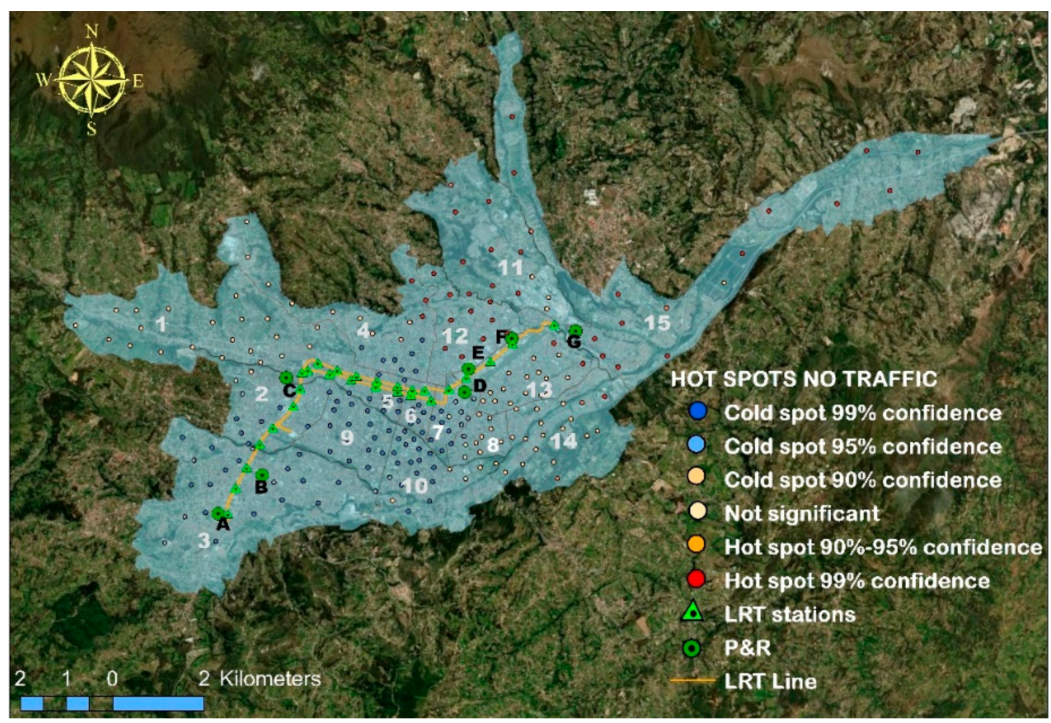

Figure 3. Hot Spots analysis without traffic. 


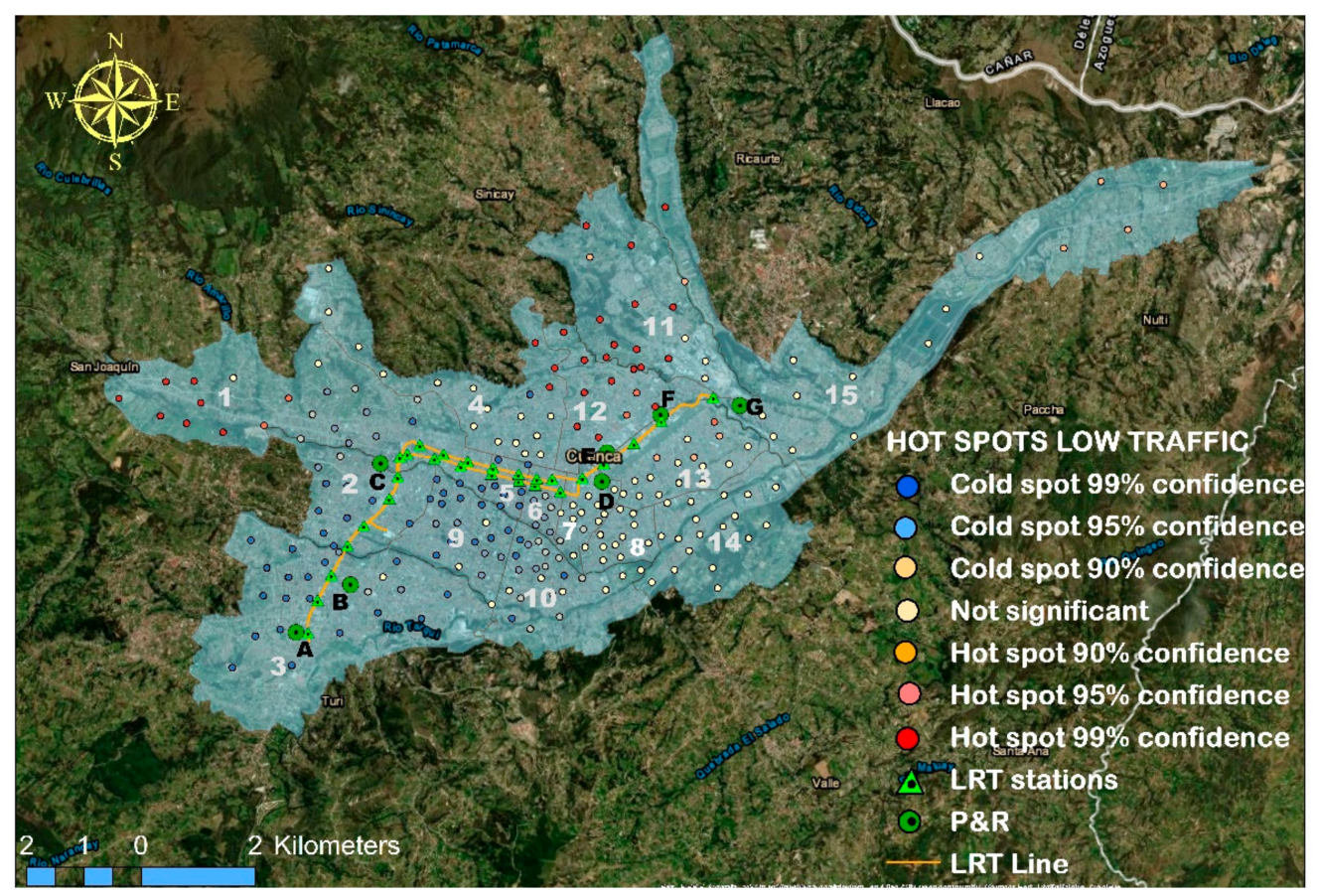

Figure 4. Hot Spots analysis low traffic.

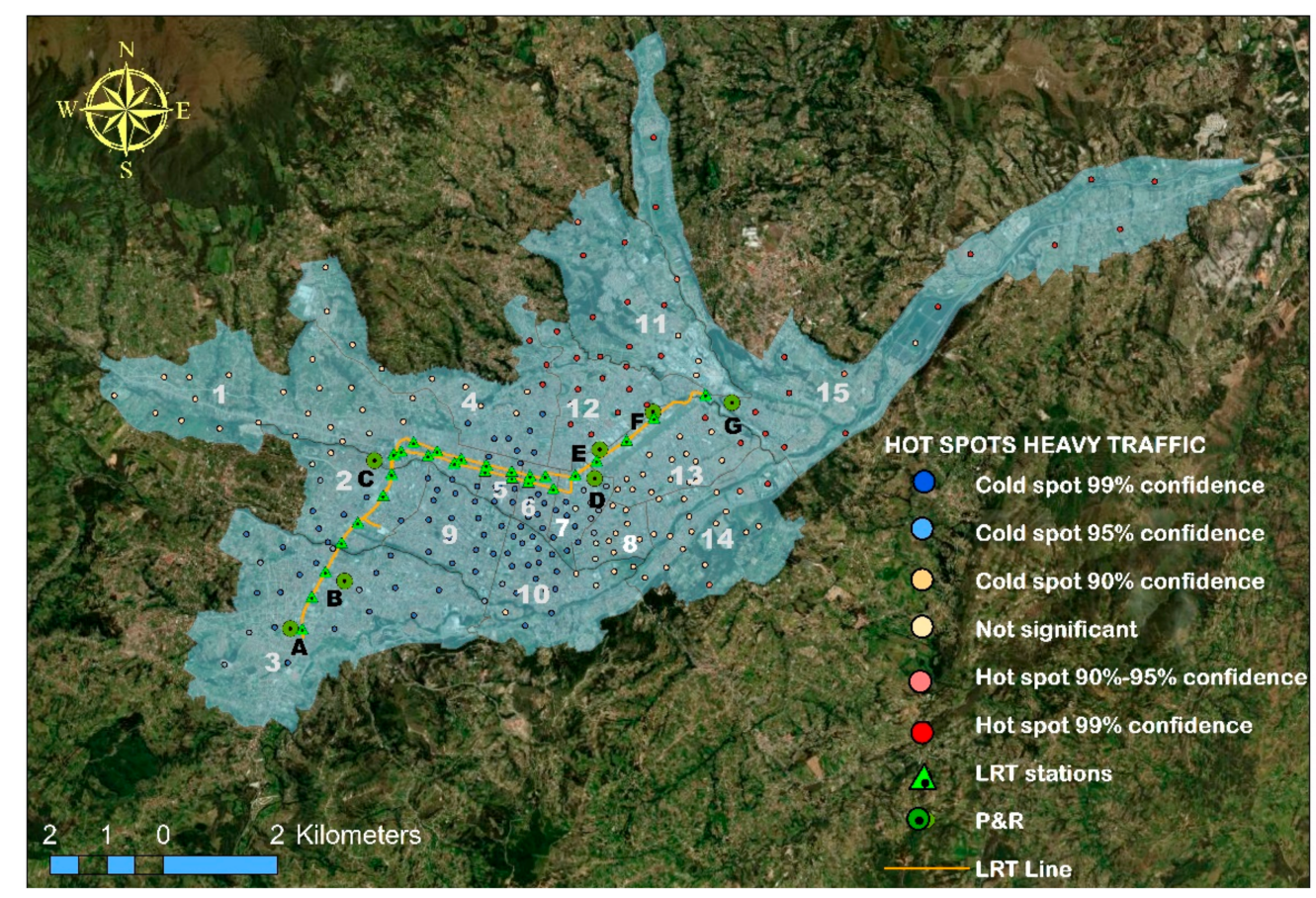

Figure 5. Hot Spots analysis heavy traffic.

The following is a description of the maps in Figures 3-5 regarding the accessibility of $P \& R$ facilities $A-G$, which varies according to traffic conditions. For example, Figure 2 shows the different origins of the trips determined for the P\&R system that has been established in the initial part of the methodology developed. Thus, zones 11, 12, and 15 are the ones that present the most problems in terms of accessibility to the P\&R system during non-traffic hours. The point is that during these hours, accessibility in terms of traffic is a result of other factors such as the form of infrastructure or the distance of the P\&R facility and the origin, or the little diffusion of the use of the P\&R system. Besides, each zone may 
have different high and low traffic hours compared to the average high and low traffic established in the city. The activity carried out in the zone may not be the competence of the potential users of the P\&R system. Users may even take other alternatives depending on the time of the day, and there may be a low concentration of use.

Indeed, in all traffic conditions, zones 11,12, and 15 have the disadvantage of accessibility to the P\&R system. However, in low traffic hours, there are accessibility problems in zone 1 as well, since this zone is the northern entry of the city. The problems might even be due to the road configuration. The main road is not connected directly to the P\&R C, and thus to reach the $P \& R$, it is necessary to take a secondary road.

At those hours, the northern entrance is more occupied by a significant number of vehicles from other cities in the country, which means a larger number of cars on the road network. Thus, many cars are entering the city; therefore, this zone is overcrowded, and the result is that drivers do not use the P\&R facility. Furthermore, in zone 14 of the southern entrance, there is a variation between greater and lesser traffic hours. However, we should consider that accessibility in the P\&R system is optimal in the other zones from a wider perspective.

As already mentioned, the second part of the journey is made by an LRT that directly connects to the destination and is not mixed with the traffic. Therefore, LRT ensures accessibility without traffic problems in the second part of the journey.

A similar analysis can be applied to cities where the P\&R system is linked to a public bus system in the second portion of the journey, which is subject to traffic conditions. Considering this complex setup, i.e., private car-P\&R system-public transport leads to a more complex analysis because of analyzing the dynamic accessibility of the private vehicle and the public transport depending on traffic conditions.

\subsection{Correlation Results}

The correlation study is necessary since it allows us to obtain parameters $z$ and $p$ that will indicate if the null hypothesis is fulfilled or not-in other words, whether we should reject the null hypothesis. The range of the Moran Index is between +1 and -1 .

Moran's index is equal to +1 , suggesting that the observed pattern is spatially clustered. If Moran's index is equal to -1 , it suggests dispersion or scattering. A Moran index close to or equal to zero points to the absence of autocorrelation.

$p$-value: it is a probability value; if this value is minimal, it means that the probability of the null hypothesis being fulfilled is minimal. The basic assumption is accepted (if $p>0.05$, and it means that the data values are randomly distributed spatially. If $p \leq 0.05$ and $z$-score is negative, the basic assumption of randomness is rejected, inferring that the high and the low values in the dataset are dispersed spatially. Similarly, the $z$ positive score assumes randomness is again rejected, and the inference drawn is that the high or low data values are spatially clustered $[60,61]$.

$Z$-value represents the standard deviations; in general, when this value is minimal (close to 0), we will not have enough statistical evidence to reject the null hypothesis.

Consequently, $z$ takes very high values (positive or negative) when the value of $p$ is small. When values tend to cluster spatially (i.e., high values cluster near other high values or low values cluster near other low values), the Moran's index will be positive; by contrast, when values are dispersed (high values tend to be near low values), the index is negative (see Table 1, Figure 6).

Table 1. Values of spatial autocorrelation reports on different measures.

\begin{tabular}{cccc}
\hline Indexes & Without Traffic & Low Traffic & High Traffic \\
\hline Moran's Index & 0.191937 & 0.174921 & 0.210636 \\
\hline$z$-value & 7.278212 (significant) & 6.617391 (significant) & 7.914015 (significant) \\
\hline$p$-value & 0.0000000 & 0.0000000 & 0.0000000 \\
\hline
\end{tabular}




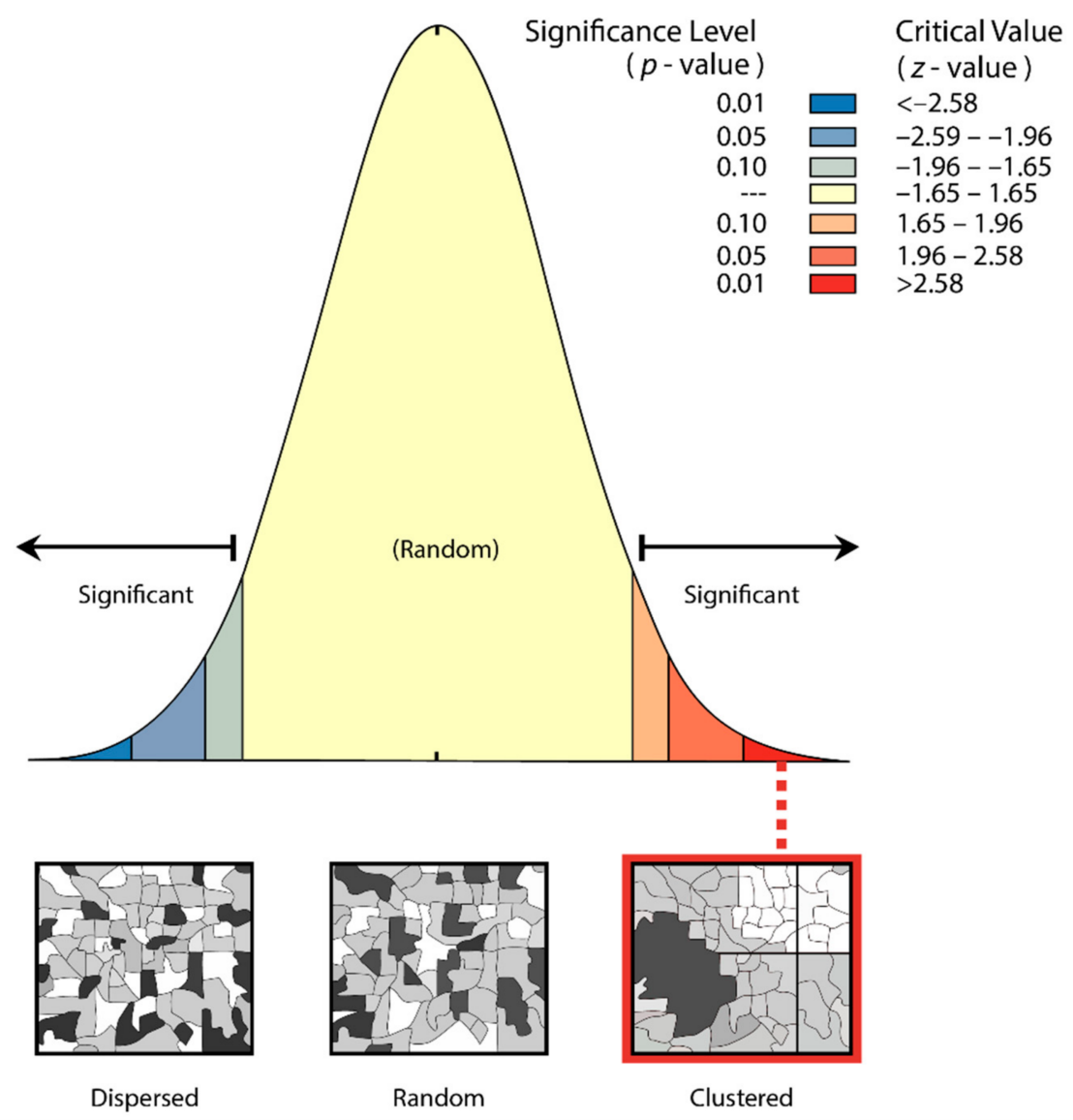

Figure 6. Correlation analysis.

The $p$-value obtained is less or equal than 0.05 for all the three scenarios, discarding the basic assumption of randomness and independence in the data values.

In all the metrics, given the high $z$-scores above, there is a less than $1 \%$ likelihood that this clustered pattern could be the result of random chance (Figure 6). The $p$-value is equal to 0 , indicating that the data values are randomly distributed spatially. Moreover, as we have explained, when the $p$-value is minimal, $z$ must take very high values. Since Moran's index is positive, we can affirm a pattern of aggregate distribution of the origins of trips in the P\&R system. The lower message indicates that, given that value of $z$, there is a $1 \%$ probability that this pattern of aggregation results from randomness. Therefore, we have enough statistical evidence to say that the origins of the P\&R system are spatially clustered.

\subsection{Dynamic Accessibility}

The final result of this dynamic study of the $P \& R$ system is that it is possible to visualize accessibility on maps (see Figures 7-9).

In Cuenca, the number of zones with good accessibility to the P\&R system is higher than that of zones with poor accessibility zones. However, four specific points in the maps indicate that a more thorough examination is required: (i) the northern access to the city in zone 1; (ii) the western access in zone 15; (iii-iv) and two sites in zone 12. The northern entry to the city in zone 1 is the main accessway to the city, which is problematic in all three scenarios due to the vast number of vehicles filling the route from the outskirts. A valid argument is that the $P \& R$ area is difficult to reach, since it is not connected directly to the main highways, but rather to the secondary roads. We propose that transport planners implement intelligent transport systems to give information about the traffic conditions to potential users of the P\&R system to minimize travel time from this zone. 


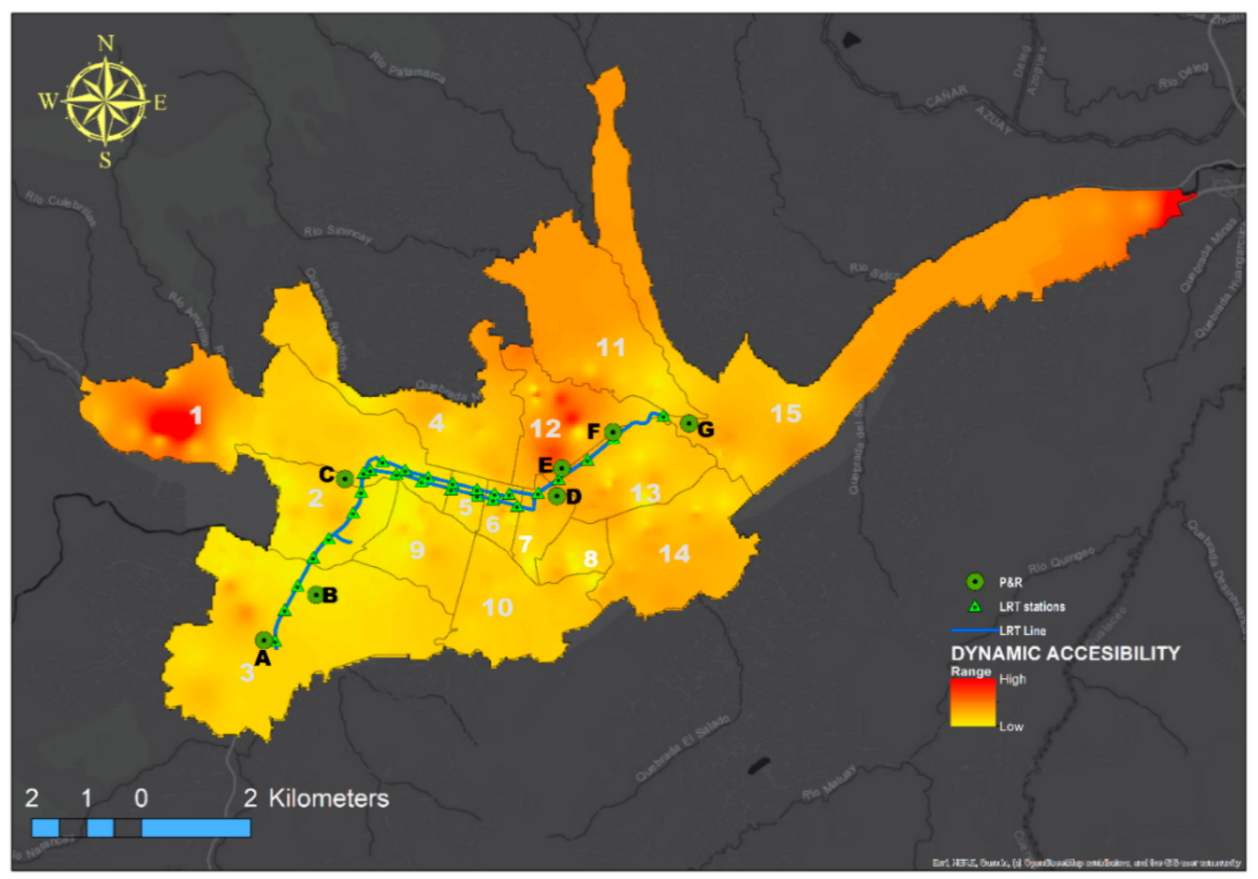

Figure 7. Dynamic accessibility analysis of the P\&R system without traffic.

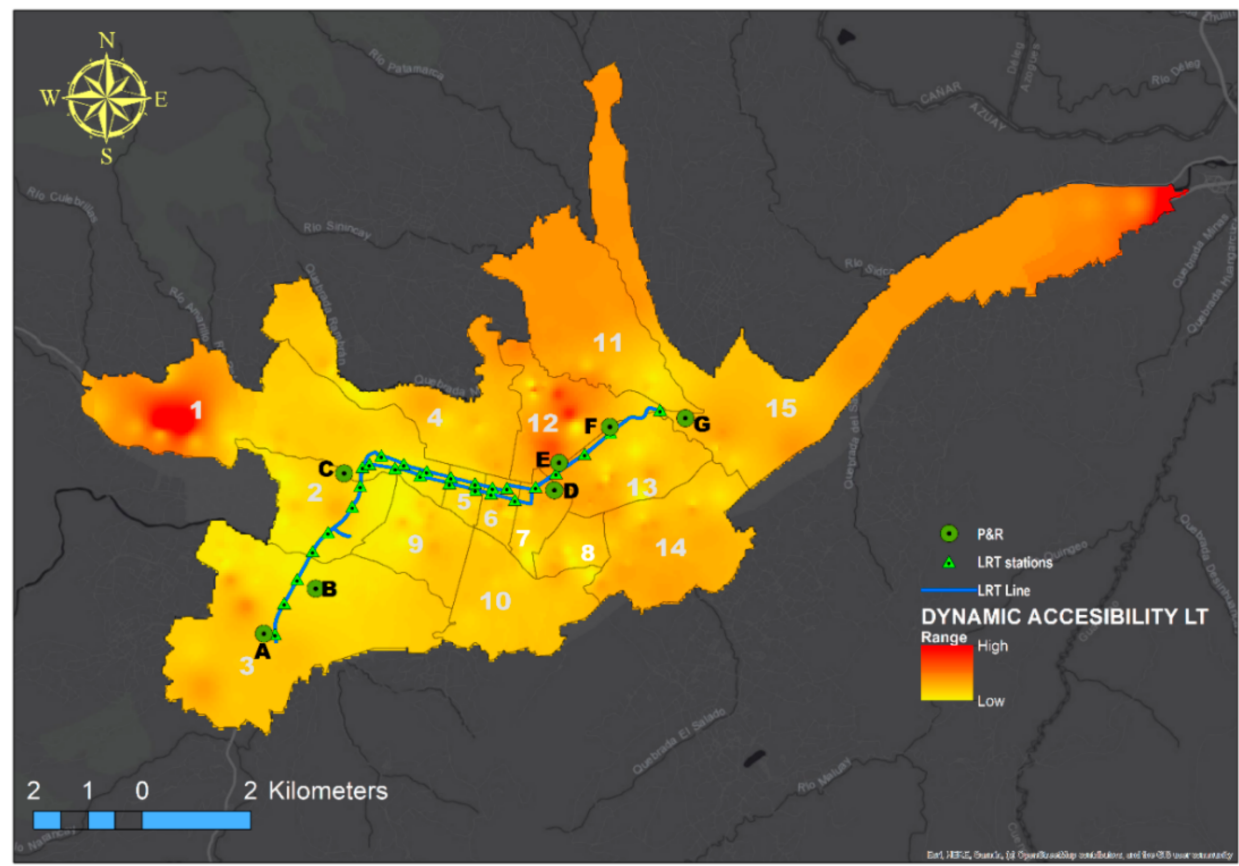

Figure 8. Dynamic accessibility analysis of the P\&R system low traffic.

The situation for zone 15 is similar to that of zone 1, as it is the western entry to the city. Cars on the road to the P\&R system often accumulate, in addition to the general assumption that it is difficult to access the P\&R system from the starting point of trips in that area. The implementation of intelligent transport systems which indicate traffic conditions allows future travelers to make the most effective journeys. 


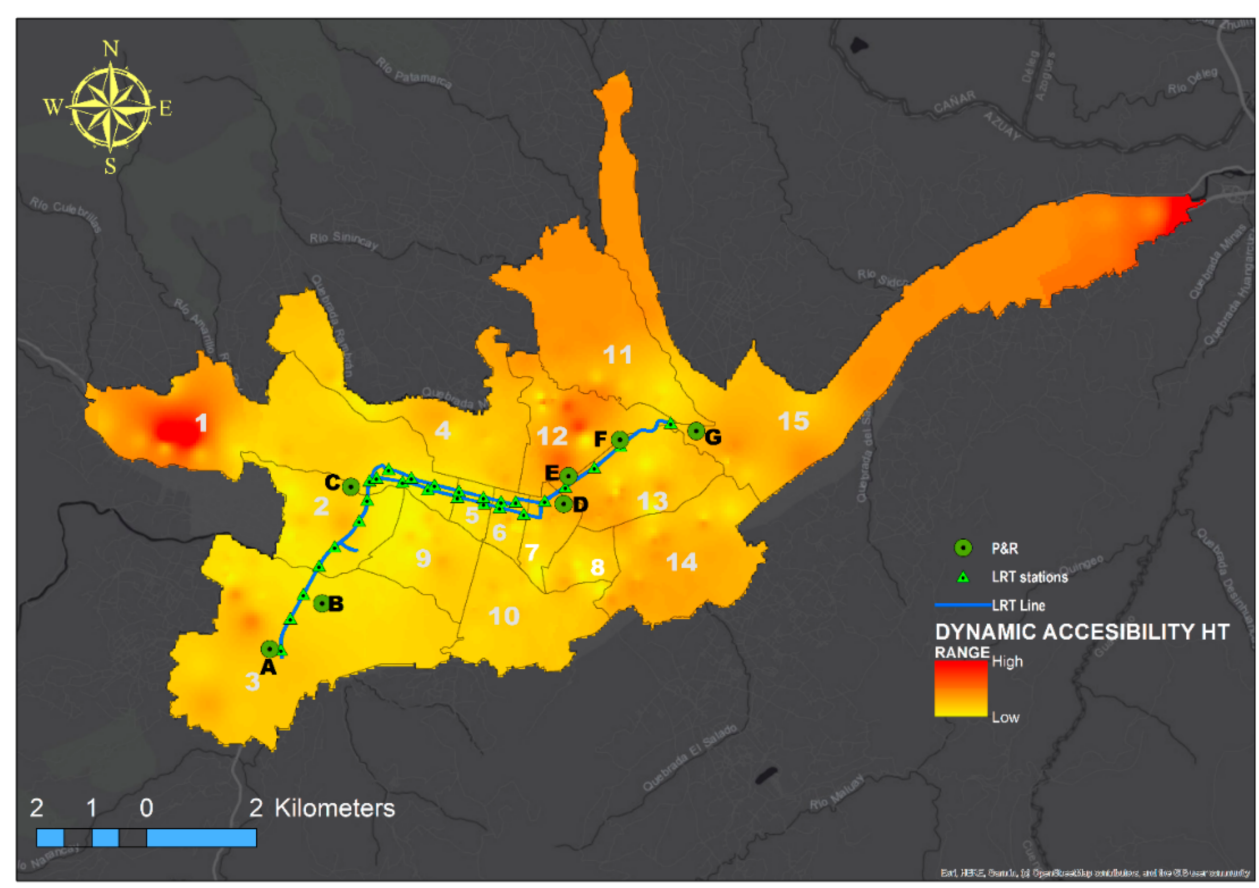

Figure 9. Dynamic accessibility analysis of the P\&R system heavy traffic.

Zone 12 is very close to the city center; therefore, the routes to the $P \& R$ system are occupied by private vehicle users who do not wish to use the P\&R system. Besides, the area is located near the bus terminal. All roads in this area are therefore occupied by private vehicles and buses. Future studies need to assess whether potential P\&R users can access the city center on foot or through the LRT.

Figure 10 presents descriptive statistics that summarize the main characteristics of travel time during a working day from morning to evening, from a starting point to a destination in different traffic conditions, using the P\&R system. Since it was decided to model the time information of the working days in Ecuador (from Monday to Friday), and there are only minor variations between the days studied, a typical working day is represented in the figure. Cuenca has three different hours of heavy traffic between 6:30 to 8:00 in the morning, 12:00 to 14:00, and 18:30 to 19:30. Therefore, the best times for users who use the $P \& R$ system are from 6:30 to 8:00, when accessibility is optimal. Figure 10 shows that at certain hours accessibility changes even though there are no traffic (NT). This suggests that during those hours there is opposite traffic. In other words, private vehicle users are leaving the $C B D$, making it difficult for potential P\&R users to access the CBD, and increasing delays. A second hypothesis is that the city has an intelligent traffic signal system that can change according to the traffic at certain times of the day, producing the same delay effect.

In the maps explained previously (Figures 7-9), it is possible to notice that the traffic affects the trips to and from the P\&R system. A variation in heavy traffic can be detected. Still, it is not excessive, and this is because a medium-sized city like Cuenca does not have significant traffic difficulties, it is rather a navigable city. However, the difference can be seen at peak periods. Therefore, this methodology becomes essential for planners in determining what actions could improve accessibility in different periods of time. Besides, providing real information about the time that the potential users of the P\&R system can start their journey with better conditions allows this information to be added as part of an intelligent transport planning of a journey through the P\&R system. In our case study, the best time to take a trip using the P\&R system is from 6:00 to 6:30 in the morning. 


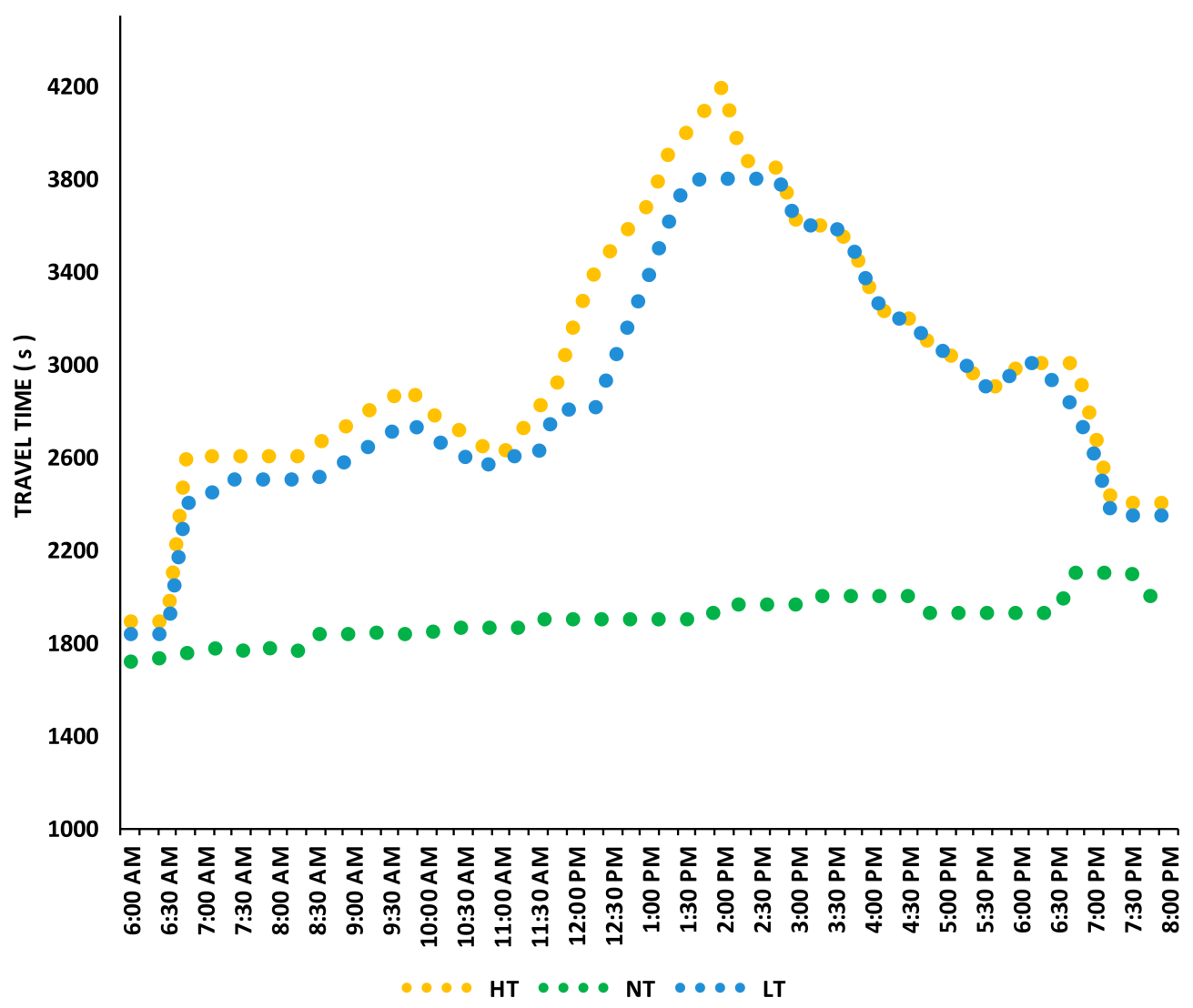

Figure 10. Dynamic accessibility time fluctuation of the P\&R system (HT-heavy traffic, NT-no traffic, LT-low traffic).

A limitation of this study is that it applies to a city with an LRT system with priority over city traffic. It would be interesting to use this methodology in a city with a bus system that shares in daily traffic and thus calculate the accessibility of public transport.

\section{Conclusions}

This study explored the accessibility of P\&R facilities in Cuenca, Ecuador. The methodology included a series of components whose starting point was the location of the origin points of the trips to the P\&R system. Then, an algorithm, which is part of the Google API, was applied. With this, the route from the origin to the facility could be defined, and the travel time could be calculated in different traffic conditions. Finally, an analysis was executed. The results were visualized through a georeferencing platform.

Several factors have been confirmed in this study that affects dynamic accessibility in the P\&R system. One of the key objectives of the algorithm was the measurement of private car traffic in the first part of the journey, before using the P\&R system. The second portion of the journey made after using the $P \& R$ system utilizes public transport, and accessibility depends on the service. Compliance with the service schedule thus makes it possible to minimize delays. In our case study, the second component of the journey through the $P \& R$ system is an LRT that has a priority over private transport.

On the one hand, each location belonging to the $P \& R$ system has different degrees of accessibility based on the place from which the passengers originate. However, this difference is not necessarily apparent, since the city of Cuenca has the same behavior every working day. To evaluate mobility, which consists of people being able to select the mode of travel they consider most appropriate, it is necessary to promote the use of P\&R with the application of intelligent transport systems that stipulate the traffic conditions to reach the destination. Considering all the information in our georeferencing software, it offers a more precise level of detail for our monitoring of improvements in accessibility at each 
origin point. Rather, over time, this leads to an increase in incorporating the P\&R system with transport planning, enabling drivers to schedule the route with technological devices and promoting sustainability to minimize travel time.

Future studies about dynamic accessibility in the $P \& R$ system may calculate the accessibility of the second part of the journey through public transport combined with traffic. Besides, this approach is interesting to extend to cities where the traffic has more notable peak and off-peak hours. We agree that the P\&R system can be integrated into travel applications. In other words, from origin to destination, most implementations imply modes of transport such as public transport, walking, and private cars. It would be important to know the outcome of integrating the P\&R system in such a manner that users living in areas with poor or no public transport coverage have the option in the urban area to change to public transport through the P\&R system.

Author Contributions: Conceptualization, J.O., J.T., and T.P.; methodology, J.O., J.T., and T.P.; software, J.O., J.T., and T.P.; validation, J.O., J.T., and T.P.; formal analysis, J.O., J.T., and T.P.; investigation, J.O., J.T., and T.P.; resources, J.O., J.T., and T.P.; data curation, J.O., J.T., and T.P.; writing-original draft preparation, J.O., J.T., and T.P.; writing—review and editing, J.O., J.T., and T.P.; visualization, J.O., J.T., and T.P.; supervision, J.O., J.T., and T.P.; project administration, J.O., J.T., and T.P.; funding acquisition, J.O., J.T., and T.P. All authors have read and agreed to the published version of the manuscript.

Funding: This research received no external funding.

Institutional Review Board Statement: Not applicable.

Informed Consent Statement: Not applicable.

Data Availability Statement: Data are contained within the article.

Acknowledgments: Special thanks to the municipality of Cuenca in Ecuador for the data supplied and to the Department of Transport Technology and Economics of the Faculty of Transportation Engineering and Vehicle Engineering of Budapest University of Technology and Economics for their collaboration and support.

Conflicts of Interest: The authors declare no conflict of interest.

\section{References}

1. Saif, M.A.; Zefreh, M.M.; Torok, A. Public transport accessibility: A literature review. Period. Polytech. Transp. Eng. 2019, 47, 36-43. [CrossRef]

2. Mavoa, S.; Witten, K.; McCreanor, T.; O'Sullivan, D. GIS based destination accessibility via public transit and walking in Auckland, New Zealand. J. Transp. Geogr. 2012, 20, 15-22. [CrossRef]

3. Martínez Sánchez-Mateos, H.S.; Givoni, M. The accessibility impact of a new High-Speed Rail line in the UK-a preliminary analysis of winners and losers. J. Transp. Geogr. 2012, 25, 105-114. [CrossRef]

4. Li, Q.; Zhang, T.; Wang, H.; Zeng, Z. Dynamic accessibility mapping using floating car data: A network-constrained density estimation approach. J. Transp. Geogr. 2011, 19, 379-393. [CrossRef]

5. Fayyaz, S.K.; Liu, X.C.; Porter, R.J. Dynamic transit accessibility and transit gap causality analysis. J. Transp. Geogr. 2017, 59, 27-39. [CrossRef]

6. García-Albertos, P.; Picornell, M.; Salas-Olmedo, M.H.; Gutiérrez, J. Exploring the potential of mobile phone records and online route planners for dynamic accessibility analysis. Transp. Res. Part A Policy Pract. 2019, 125, 294-307. [CrossRef]

7. Ortega, J.; Tóth, J.; Péter, T.; Moslem, S. An Integrated Model of Park-And-Ride Facilities for Sustainable Urban Mobility. Sustainability 2020, 12, 4631. [CrossRef]

8. Ortega, J.; Hamadneh, J.; Esztergár-Kiss, D.; Tóth, J. Simulation of the Daily Activity Plans of Travelers Using the Park-and-Ride System and Autonomous Vehicles: Work and Shopping Trip Purposes. Appl. Sci. 2020, 10, 2912. [CrossRef]

9. Duncan, M.; Christensen, R.K. An analysis of park-and-ride provision at light rail stations across the US. Transp. Policy 2013, 25, 148-157. [CrossRef]

10. Lin, T.; Xia, J.; Robinson, T.P.; Goulias, K.G.; Church, R.L.; Olaru, D.; Tapin, J.; Han, R. Spatial analysis of access to and accessibility surrounding train stations: A case study of accessibility for the elderly in Perth, Western Australia. J. Transp. Geogr. 2014, 39, 111-120. [CrossRef]

11. Carlson, K.; Owen, A. Accessibility Impacts of Park-and-Ride Systems. Transp. Res. Rec. 2019, 2673, 72-82. [CrossRef]

12. Guan, J.; Zhang, K.; Shen, Q.; He, Y. Dynamic Modal Accessibility Gap: Measurement and Application Using Travel Routes Data. Transp. Res. Part D Transp. Environ. 2020, 81, 102272. [CrossRef] 
13. Farhan, B.; Murray, A.T. A GIS-Based Approach for Delineating Market Areas for Park and Ride Facilities. Trans. GIS 2005, 9, 91-108. [CrossRef]

14. Liu, Z.; Meng, Q. Bus-based park-and-ride system: A stochastic model on multimodal network with congestion pricing schemes. Int. J. Syst. Sci. 2014, 45, 994-1006. [CrossRef]

15. Park, J.; Lee, D.; Park, C.; Kim, H.; Jung, T.; Kim, S. Park Accessibility Impacts Housing Prices in Seoul. Sustainability 2017, 9, 185. [CrossRef]

16. Ortega, J.; Tóth, J.; Péter, T. Estimation of parking needs at Light Rail Transit System stations. In Proceedings of the Conference on Transport Sciences 2019, Győr, Hungary, 22-23 March 2019; p. 8.

17. Horváth, M.T.; Mátrai, T.; Tóth, J. Route Planning Methodology with Four-step Model and Dynamic Assignments. Transp. Res. Proc. 2017, 27, 1017-1025. [CrossRef]

18. Geurs, K.; Zondag, B.; de Jong, G.; de Bok, M. Accessibility appraisal of land-use/transport policy strategies: More than just adding up travel-time savings. Transp. Res. Part D Transp. Environ. 2010, 15, 382-393. [CrossRef]

19. Hansen, W.G. How Accessibility Shapes Land Use. J. Am. Plan. Assoc. 1959, 25, 73-76. [CrossRef]

20. Rześny-Cieplińska, J.; Szmelter-Jarosz, A.; Moslem, S. Priority-based stakeholders analysis in the view of sustainable city logistics: Evidence for Tricity, Poland. Sustain. Cities Soc. 2021, 67, 102751. [CrossRef]

21. Kutlu Gündoğdu, F.; Duleba, S.; Moslem, S.; Aydın, S. Evaluating public transport service quality using picture fuzzy analytic hierarchy process and linear assignment model. Appl. Soft Comput. 2021, 100, 106920. [CrossRef]

22. Yigitcanlar, T.; Sipe, N.; Evans, R.; Pitot, M. A GIS-based land use and public transport accessibility indexing model. Aust. Plan. 2007, 44, 30-37. [CrossRef]

23. Kujala, R.; Weckström, C.; Mladenović, M.N.; Saramäki, J. Travel times and transfers in public transport: Comprehensive accessibility analysis based on Pareto-optimal journeys. Comput. Environ. Urban Syst. 2018, 7, 41-54. [CrossRef]

24. Farber, S.; Fu, L. Dynamic public transit accessibility using travel time cubes: Comparing the effects of infrastructure (dis)investments over time. Comput. Environ. Urban Syst. 2017, 62, 30-40. [CrossRef]

25. Li, W.; Luo, Q.; Zephaniah, S.; Liu, Z. Evaluating the Dynamic Accessibility of Metro Systems in Overcrowded Conditions. Transp. Res. Rec. 2020, 2674, 42-52.

26. Straatemeier, T.; Bertolini, L. How can planning for accessibility lead to more integrated transport and land-use strategies? Two examples from the Netherlands. Eur. Plan. Stud. 2020, 28, 1713-1734. [CrossRef]

27. Jiang, S.; Guan, W.; He, Z.; Yang, L. Measuring taxi accessibility using grid-based method with trajectory data. Sustainability 2018, 10, 3187. [CrossRef]

28. Wu, X.; Lu, Y.; Lin, Y.; Yang, Y. Measuring the destination accessibility of cycling transfer trips in metro station areas: A big data approach. Int. J. Environ. Res. Public Health 2019, 16, 2641. [CrossRef]

29. Huang, Z.; Xu, R.; Fan, W.D.; Zhou, F.; Liu, W. Service-oriented load balancing approach to Alleviating Peak-Hour congestion in a metro network based on multi-path accessibility. Sustainability 2019, 11, 1293. [CrossRef]

30. Geurs, K.T.; La Paix, L.; Van Weperen, S. A multi-modal network approach to model public transport accessibility impacts of bicycle-train integration policies. Eur. Transp. Res. Rev. 2016, 8, 1-15. [CrossRef]

31. Xia, N.; Cheng, L.; Chen, S.; Wei, X.Y.; Zong, W.W.; Li, M.C. Accessibility based on Gravity-Radiation model and Google Maps API: A case study in Australia. J. Transp. Geogr. 2018, 72, 178-190. [CrossRef]

32. Bimpou, K.; Ferguson, N.S. Dynamic accessibility: Incorporating day-to-day travel time reliability into accessibility measurement. J. Transp. Geogr. 2020, 89, 102892. [CrossRef]

33. Benenson, I.; Martens, K.; Rofé, Y.; Kwartler, A. Public transport versus private car GIS-based estimation of accessibility applied to the Tel Aviv metropolitan area. Ann. Reg. Sci. 2011, 47, 499-515. [CrossRef]

34. Salonen, M.; Toivonen, T. Modelling travel time in urban networks: Comparable measures for private car and public transport. J. Transp. Geogr. 2013, 31, 143-153. [CrossRef]

35. Williams, R. Oxford's park-and-ride system. Proc. Inst. Civ. Eng. Munic. Eng. 1999, 133, 127-135. [CrossRef]

36. Liu, T.-L.; Huang, H.-J.; Yang, H.; Zhang, X. Continuum modeling of park-and-ride services in a linear monocentric city with deterministic mode choice. Transp. Res. Part B Methodol. 2009, 43, 692-707. [CrossRef]

37. Dickins, I.S.J. Park and ride facilities on light rail transit systems. Transportation 1991, 18, 23-36. [CrossRef]

38. Parkhurst, G. Park and ride: Could it lead to an increase in car traffic? Transp. Policy 1995, 2, 15-23. [CrossRef]

39. Wang, J.Y.T.; Yang, H.; Lindsey, R. Locating and pricing park-and-ride facilities in a linear monocentric city with deterministic mode choice. Transp. Res. Part B Methodol. 2004, 38, 709-731. [CrossRef]

40. Ortega, J.; Tóth, J.; Péter, T. Mapping the Catchment Area of Park and Ride Facilities within Urban Environments. ISPRS Int. J. Geo. Inf. 2020, 9, 501. [CrossRef]

41. Ortega, J.; Tóth, J.; Moslem, S.; Péter, T.; Duleba, S. An Integrated Approach of Analytic Hierarchy Process and Triangular Fuzzy Sets for Analyzing the Park-and-Ride Facility Location Problem. Symmetry 2020, 12, 1225. [CrossRef]

42. Ortega, J.; Moslem, S.; Tóth, J.; Péter, T.; Palaguachi, J.; Paguay, M. Using Best Worst Method for Sustainable Park and Ride Facility Location. Sustainability 2020, 12, 10083. [CrossRef]

43. Song, Z.; He, Y.; Zhang, L. Integrated planning of park-and-ride facilities and transit service. Transp. Res. Part C Emerg. Technol. 2017, 74, 182-195. [CrossRef] 
44. Chen, X.; Kim, I. Modelling Rail-Based Park and Ride with Environmental Constraints in a Multimodal Transport Network. J. Adv. Transp. 2018, 2018, 1-15. [CrossRef]

45. Ni, A.; Lin, X.; Luo, J. Stochastic Traffic Assignment Model Considering Park \& Ride Network and Travel Time Reliability. In Lecture Notes in Electrical Engineering; Springer: Singapore, 2018; Volume 419, pp. 873-886.

46. Du, B.; Wang, D.Z.W. Continuum modeling of park-and-ride services considering travel time reliability and heterogeneous commuters-A linear complementarity system approach. Transp. Res. Part E Logist. Transp. Rev. 2014, 71, 58-81. [CrossRef]

47. Cavadas, J.; Antunes, A.P. An optimization model for integrated transit-parking policy planning. Transportation 2019, 46, 1867-1891. [CrossRef]

48. Farhan, B.; Murray, A.T. Siting park-and-ride facilities using a multi-objective spatial optimization model. Comput. Oper. Res. 2008, 35, 445-456. [CrossRef]

49. Holguín-Veras, J.; Reilly, J.; Aros-Vera, F.; Yushimito, W.; Isa, J. Park-and-Ride Facilities in New York City. Transp. Res. Rec. J. Transp. Res. Board 2012, 2276, 123-130. [CrossRef]

50. Holguı'n-Veras, J.; Yushimito, W.F.; Aros-Vera, F.; Reilly, J.J. User rationality and optimal park-and-ride location under potential demand maximization. Transp. Res. Part B Methodol. 2012, 46, 949-970. [CrossRef]

51. Horner, M.W.; Grubesic, T.H. A GIS-based planning approach to locating urban rail terminals. Transportation 2001, $28,55-77$. [CrossRef]

52. Lin, T.; Xia, J.; Robinson, T. Spatial Analysis of Park and Ride Users' Dynamic Accessibility to Train Station: A Case Study in Perth. Int. J. Transp. Veh. Eng. 2017, 11, 359-368.

53. Ortega, J.; Tóth, J.; Péter, T. A spatial study of the catchment area of P\&R facilities. In Proceedings of the X International Conference on Transport Sciences Győr 2020, Győr, Hungary, 29-30 October 2020; p. 20.

54. Orellana, D.; Guerrero, M.L. Exploring the influence of road network structure on the spatial behaviour of cyclists using crowdsourced data. Environ. Plan. B Urban Anal. City Sci. 2019, 46, 1314-1330. [CrossRef]

55. Hermida, C.; Cordero, M.; Orellana, D. Analysis of the influence of urban built environment on pedestrian flow in an intermediatesized city in the Andes of Ecuador. Int. J. Sustain. Transp. 2019, 13, 777-787. [CrossRef]

56. Cuenca Municipality. Sustainable Urban Mobility Plan and Public Areas, I; Cuenca Municipality: Cuenca, Ecuador, 2014.

57. Municipio de Cuenca. El Plan de Desarrollo y Ordenamiento Territorial del Cantón Cuenca Azuay; Municipio de Cuenca: Cuenca, Ecuador, 2018.

58. Google Inc. Google Maps Directions API Service. Available online: https://developers.google.com/maps?hl=es-419 (accessed on 8 May 2019).

59. Moran, P.A.P. Notes on Continuous Stochastic Phenomena. Biometrika 1950, 37, 17-23. [CrossRef]

60. Yang, Q.; Zhang, H.; Bai, W.; Liu, W. County-Scale Migration Attractivity and Factors Analysis. In Proceedings of the 26th International Conference on Geoinformatics, Kunming, China, 28-30 June 2018; pp. 1-7.

61. Kumari, M.; Sarma, K.; Sharma, R. Using Moran's I and GIS to study the spatial pattern of land surface temperature in relation to land use/cover around a thermal power plant in Singrauli district, Madhya Pradesh, India. Remote Sens. Appl. Soc. Environ. 2019, 15, 100239. [CrossRef] 